\title{
Neoliberalismo e as recodificações do desejo em favor do trabalho pós-fordista
}

\author{
Neoliberalism and the recodifications of desire \\ forward post-fordism work
}

\section{Breilla Zanon ${ }^{1}$}

\begin{abstract}
RESUMO
O objetivo desse artigo é realizar uma análise teórico-filosófica a respeito da localização do discurso do amor ao trabalho dentro das sociedades capitalistas atuais. Iremos refletir sobre como as relações trabalhadortrabalho foram ressignificadas ao longo da história e transformadas em algo que alimenta as próprias engrenagens capitalistas em sua fase pósindustrial marcada pelos valores do neoliberalismo.
\end{abstract}

PALAVRAS-CHAVE: Trabalho Flexível. Neoliberalismo. Empreendedorismo de Si.

\begin{abstract}
The aim of this article is to carry out a theoretical and philosophical analysis about the location of the discourse of love related to work within current capitalist societies. We will reflect on how worker-labor relations have been reframed throughout history and transformed into something that feeds the capitalist gears itself in its post-industrial phase marked by the values of neoliberalism.
\end{abstract}

KEYWORDS: Flexible Work. Neoliberalism. Self-entrepreneurship.

\section{Uma breve introdução filosófica sobre desejo e trabalho na modernidade}

Falar sobre os afetos do trabalhador em relação ao seu trabalho é um desafio. Não se trata somente de colocar em análise ou julgamento a subjetividade desse trabalhador partindo do princípio objetivo de suas relações de trabalho. De partida, entendemos que discursos como faça o que

\footnotetext{
${ }^{1}$ Graduada e Mestre em Ciências Sociais pela Universidade Federal de Uberlândia - UFU, doutora em Sociologia pela Universidade Federal de São Carlos - UFSCar e pesquisadora do Laboratório de Estudos sobre Trabalho, Profissões e Mobilidades - LEST-M/UFSCar. Atualmente é Secretária de Mídias e Comunicação da Sociedade Brasileira de Sociologia (SBS).
} 
você ama é resultado de um processo histórico. Por isso, ao pensarmos a relação existente entre o trabalho e o amor, somos levados a refletir sobre os princípios do prazer e do desejo que fazem de uma dimensão tão objetiva quanto o trabalho um plano aonde agora poderiam ser desenvolvidas emoções alinhadas ao prazer pela produtividade da vida capitalista. $\mathrm{O}$ presente artigo traz reflexões que compõem o trabalho de pesquisa da tese Não era amor, era cilada: startups, coworkings e a mobilização do desejo pelo mundo do trabalho ${ }^{2}$ (ZANON, 2019), apontando alguns elementos e condições históricas sobre como foi possível que uma atividade racional como o trabalho, que havia até então sido limitada às relações de disciplina, produtividade e alienação no contexto da modernidade, se encontre agora ressignificada e transformada em algo que alimenta o espírito dos trabalhadores de forma desejante nas sociedades capitalistas pós-industriais.

Quando pensamos sobre os princípios de prazer e produtividade presentes na formação das sociedades modernas ocidentais, algumas observações preliminares devem ser feitas e para isso recorremos à Marcuse (1975) em Eros e a civilização: uma interpretação filosófica do pensamento de Freud. Marcuse se utiliza das obras e estudos de Sigmund Freud acerca da relação entre libido e civilização a fim de encarar ambos como uma organização histórica específica do homem em sociedade. É importante esclarecer que nessa obra, Marcuse (1975) tem como objetivo contribuir para a filosofia da psicanálise e não para suas técnicas em si. Assim como o que se pretende aqui, não se trata de buscar um diagnóstico acerca de indivíduos, mas de travar uma reflexão geral acerca da sociedade e os valores que ela invoca, bem como sua finalidade.

Assim como Marcuse (1975), Erich Fromm (2000) nos ajuda a fundamentar as especificidades e a essência dos significados do amor nas sociedades modernas. Em seus estudos sobre o amor como valor nessas sociedades, Fromm (2000) aponta para a importância de uma análise a respeito da temporalidade e do contexto dos esquemas de significação que

\footnotetext{
${ }^{2}$ Tese apresentada como conclusão do Doutorado em Sociologia pelo Programa de Pós-graduação em Sociologia da Universidade Federal de São Carlos - PPGS/UFSCar, no ano de 2019.
} 
compõe as diferentes sociedades em suas temporalidades. Podemos dizer que Fromm (2000) - assim como Marcuse (1975) - vai ao encontro da perspectiva antropológica elaborada por Sahlins $(2011)^{3}$, quando observa que "a capacidade de amar, num indivíduo que viva em qualquer cultura dada, depende dessa cultura sobre o caráter da pessoa comum" (FROMM, 2000, p. 65). O que queremos demonstrar, em linhas gerais por meio desses três autores é que, cada um em sua perspectiva e abordagem, considera uma ancoragem histórica do simbólico que, para além das relações materiais, corresponde a uma construção dialógica das relações sociais em suas diversas dimensões de interpretação da realidade.

Dito isso, aprofundamos na reflexão sobre a transformação histórica dos significados dessa relação. Marcuse (1975) observa que para Freud, a civilização se constrói a partir da transformação do princípio do prazer em princípio de realidade (MARCUSE, 1975):

O homem animal converte-se em ser humano somente através de uma transformação fundamental da sua natureza, afetando não só os anseios instintivos, mas também os valores instintivos, isto é, os princípios que governam a consecução dos anseios. A transformação no sistema dominante de valores pode ser assim definida, de um modo probatório:

De: satisfação imediata, prazer, júbilo (atividade lúdica), receptividade, ausência de repressão, Para: satisfação adiada, restrição do prazer, esforço (trabalho), produtividade, segurança

[...] O indivíduo chega à compreensão de que uma plena e indolor gratificação de suas necessidades é impossível. E, após essa experiência de desapontamento, um novo princípio de realidade supera o princípio de prazer: o homem aprende a renunciar o prazer momentâneo, incerto e destrutivo, substituindo-o pelo prazer adiado, restringido, mas "garantido" (MARCUSE, 1975, 33-34)

\footnotetext{
3 "A história é ordenada culturalmente de diferentes modos nas diversas sociedades, de acordo com os esquemas de significação das coisas" (SAHLINS, 2011, p. 7)
} 
No entanto, quando olhamos em específico para o significado que o amor e o desejo tomaram em meio as relações contemporâneas no que diz respeito aos seus valores abarcados pela objetividade do mundo do trabalho, nosso argumento é de que essa concepção também se revela transformada. Se pensarmos o amor - elemento do prazer - não como simples valor subjetivo, mas como um dos componentes presentes em relações sociais historicamente definidas e, dessa maneira, um elemento a ser pensado como socialmente construído, somos então levados a encarar o fato de que houve uma mudança de sentido na construção de realidade proposta por Freud. Essa mudança é ainda mais visível se deslocarmos esse conceito de realidade para o mundo do trabalho. Vemos que as formas de trabalho pós-fordistas - definidas especialmente pela busca da flexibilização não só da produção, mas das relações de trabalho como forma de aumentar a produtividade frente aos entraves da rigidez das sociedades industriais - se encontram contextualizadas em meio as relações de consumo material e simbólica. Como veremos adiante, elas revelam o caminho inverso daquele teorizado por Freud: a transformação da satisfação adiada torna-se imediata, a restrição do prazer em produção do prazer, o esforço em júbilo, a produtividade em receptividade, a segurança em ausência de repressão ${ }^{4}$. Entender essa recodificação é fundamental para entender as transformações das bases produtivas e dos princípios de realidade da sociedade pós-fordista.

Marcuse (1975), de forma complementar, também se atenta ao fato de que Freud leva em consideração a interferência da história sobre os instintos e como tal, podemos dizer que essa interferência se revela também nas construções dos desejos de maneira contextualizada, ou seja, sua natureza se encontra sujeita a mudanças.

Mas não existirão, nos próprios instintos, forças associais que necessitam de uma coação repressiva, independentemente da escassez ou abundância no mundo externo? Uma vez mais, recordamos a afirmação de Freud de que a

\footnotetext{
${ }^{4}$ É preciso dizer que, a obra sob a qual fazemos referência a Freud é o Mal-estar da civilização, lançada em 1929, ou seja, em um momento em que imperavam as relações fordistas de produção.
} 
natureza dos instintos é historicamente adquirida. Portanto, essa natureza está sujeita a mudanças, se as condições fundamentais que foram a causa dos instintos adquirirem tal natureza tiverem também mudado. (MARCUSE, 1975, p. 128)

Nosso objetivo é trazer essas observações para o contexto pós-fordista e neoliberal de nossa contemporaneidade. Na esteira de Laval \& Dardot (2016), observamos as transformações dos princípios que regem as racionalidades humanas. Nos deparamos agora com um outro momento, sobretudo cultural, que cada vez mais explora a ideia da existência de uma livre escolha, usando para isso fórmulas e discursos capazes de reagir diretamente sobre a subjetividade dos sujeitos. Mesmo que a liberdade humana - a liberdade dos desejos como valores - tenha sido indubitavelmente uma bandeira levantada pelos movimentos sociais contra-hegemônicos, paradoxalmente, foi o capitalismo que conseguiu disseminar esse valor como uma ideologia a ser consumida, legitimando a verdade de que essa seria a única plataforma por meio da qual a liberdade poderia se concretizar.

Enunciados econômicos e enunciados do tipo "psi” juntaram-e para dar ao novo sujeito a forma do arbítrio supremo entre "produtos" e estilos diferentes no grande mercado dos códigos e valores. Foi ainda essa conjunção que deu origem a essas técnicas de si que visam ao desempenho individual por meio de uma racionalização gerencial do desejo. Mas foi outra modalidade dessa conjunção que permitiu o desenvolvimento do dispositivo de desempenho/gozo, uma modalidade que consiste não em perguntar em que medida o indivíduo e a empresa, cada qual com suas exigências próprias, podem adaptar-se um ao outro, mas como o sujeito psicológico e o sujeito da produção podem identificar-se. Para falar em termos freudianos, a questão não é mais fazer com que os indivíduos passem do princípio do prazer ao princípio de realidade - o objetivo terapêutico dos partidários de uma psicanálise "adaptativa" que promete um acréscimo de "felicidade" para os mais bem adaptados; a questão agora é fazer os indivíduos passarem do princípio do prazer ao além do princípio do prazer. A identificação entre os dois sujeitos distancia-se do horizonte homeostático do equilíbrio para operar 
na lógica da intensificação e da ilimitação. [...] A liberdade tornou-se uma obrigação de desempenho. O normal não é mais o domínio e a regulação das pulsões, mas sua estimulação intensiva como principal forma de energia. (LAVAL \& DARDOT, 2016, p. 360-361)

A introdução filosófica a qual recorremos aqui, portanto, tem como intuito lançar luz a uma mudança das significações que limitavam até então, o mundo do trabalho à esfera da contenção do prazer. Ser livre torna-se agora um elemento que dá base à construção da subjetividade do trabalhador quanto sujeito em relação ao seu trabalho. No entanto, como veremos a diante, não se trata de uma livre fruição dos desejos, mas de uma concentração dos mesmos na dimensão da produtividade ligada ao trabalho, pois, sob essa regulação, a liberdade só se concretiza quando pavimentada sob a lógica do mercado.

\section{Primeiras inserções do discurso do amor ao trabalho}

A não-repressão bem como a condução das paixões como elementos capazes de libertar o homem da rotinização imposta pelo trabalho faz parte das construções teóricas desenvolvidas por Charles Fourier (1772-1837), um dos primeiros pensadores a salientar a orientação dos afetos em função do trabalho. Considerado também como um filósofo e um dos precursores do socialismo utópico ao lado de Robert Owen e Henri Saint-Simon, Fourier apresenta em sua obra Le nouveau monde industriel et societaire (1973) a ideia das falanges e dos falanstérios. As falanges corresponderiam "a pequenas unidades sociais com populações de cerca de 1500 habitantes, e cada uma possuiria um edifício comum chamado Falanstério no qual todos viveriam harmoniosamente" (BARROS, 2011, p. 246).

Mas o que faz de Fourier um dos primeiros pensadores a respeito da relação amor-trabalho é sua ideia sobre como essas duas dimensões, dentro dos falanstérios, deveriam se fundamentar dentro daquilo que ele chama de teoria da atração passional. Fourier propunha com essa teoria realizar uma crítica ao trabalho industrial, tido para ele como repugnante uma vez que é 
"negativo de tudo o que idealiza como trabalho atraente e conforme os gostos, às paixões, às inclinações dos indivíduos e de seus grupos" (ALBORNOZ, p. 16). Um dos traços mais importantes e interessantes trazido por Fourier no que tange à atração passional pelo trabalho é que este estaria condicionado à superação das relações de submissão e dominação. Dessa forma, a paixão pelo trabalho se daria apenas se tais relações estivessem rompidas. Em suas palavras:

Todo comando arbitrário é humilhante para aquele que obedece. O indivíduo em harmonia somente é comandado por disciplina convencionada, coletiva, e consentida apaixonadamente; neste caso, nada há de arbitrário na ordem dada, nada de ofensivo na obediência; enquanto que o método civilizado ou regime de domesticidade individual e assalariada cria sempre uma discórdia dupla, frequentemente quádrupla, lá onde o método societário produz duplo ou quádruplo charme, elos e acordos de toda espécie. (FOURIER, 1973, p.299)

Fourier considerava que a educação seria um catalizador, essencial para promover desde a mais tenra idade a paixão e a consecutiva potencialidade em relação às atividades produtivas desse sujeito (ALBORNOZ, 2007 p.21-22). Fourier queria superar a civilização industrial e os males que esta havia despejado sobre as sociedades modernas, sendo o maior deles o impedimento da realização das paixões dos indivíduos. Podemos dizer que a crítica à dominação implementada pelas relações fordistas de trabalho desenvolvidas a partir dos últimos anos da década de 60 levantam problematizações que vão ao encontro do que havia sido proposto por Fourier muitos anos antes. Mais que isso, é possível observar também a importância que Fourier dava a elementos não materiais, como a educação, na realização e ampliação dessa autonomia do trabalhador. Para ele, a variedade de paixões, ou as paixões distributivas como declarava conceitualmente, era importante para a harmonia dos indivíduos em sociedade (MARQUES, 2000)

Complementar à ideia de Fourier, Marcuse (1985) observa que havia um “conflito irreconciliável”, não entre o trabalho como princípio de realidade e o Eros como princípio de prazer, mas entre o trabalho alienado, que para ele 
se constituía como princípio de desempenho, e o Eros, entendido como prazer.

Partindo da ideia de uma nova racionalidade que governa não só os corpos, mas a própria alma dos trabalhadores, podemos dizer que ainda assim existe uma racionalização dos desejos dos indivíduos em sociedade, mas não pelo viés da repressão, e sim pela intensa busca por satisfação de necessidades objetivas coerentes ao capital e internalizadas como interesses subjetivos pelo trabalhador. É por meio do trabalho que a transformação da racionalidade mobiliza desejos que interessam às engrenagens produtivas.

Figura 1 e 2 - Parede com mensagens motivacionais no Campus São Paulo (São Paulo, SP) 5
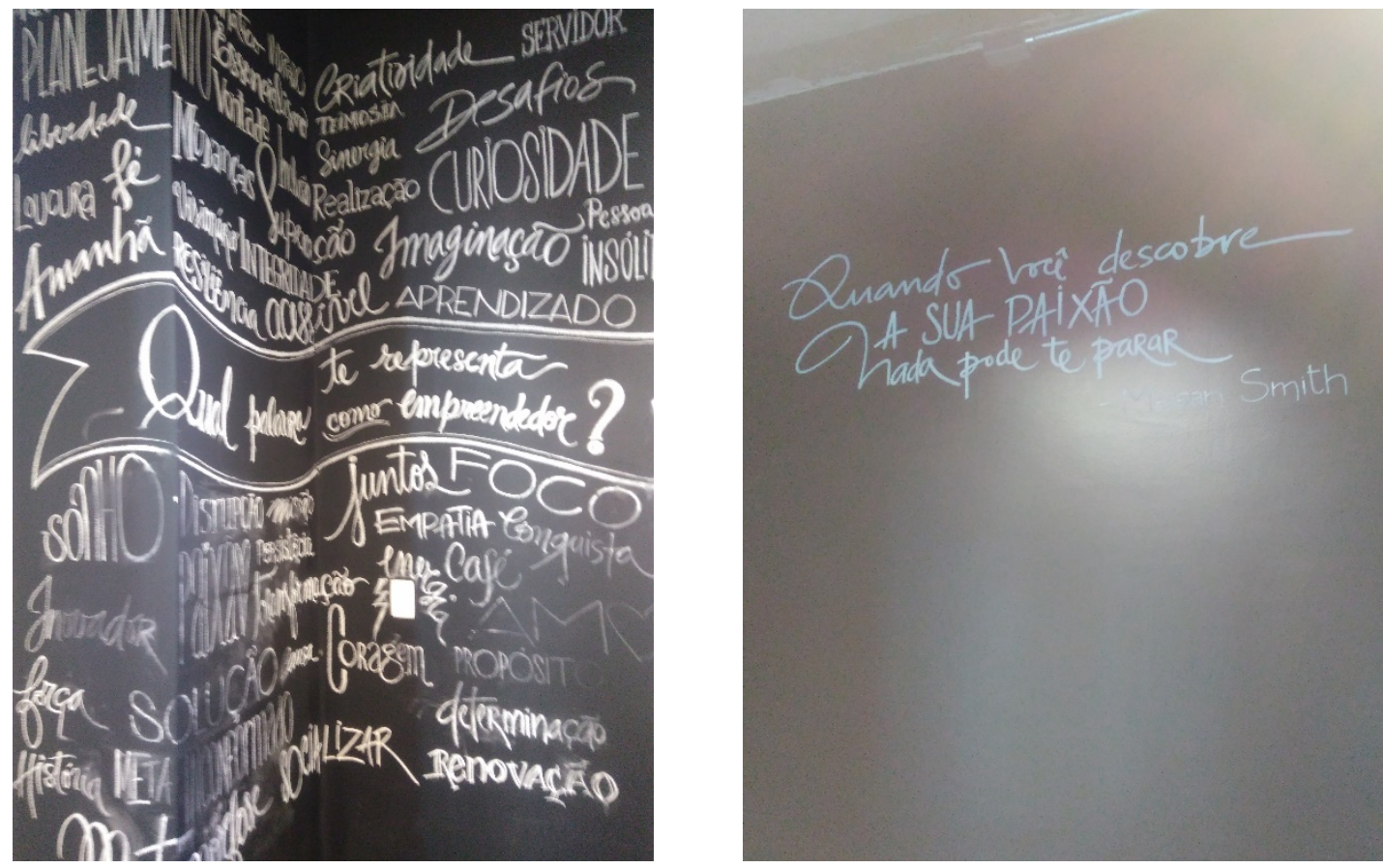

Fonte: Foto da autora

\footnotetext{
${ }^{5}$ Essas fotos fazem parte do diário de campo realizado na elaboração da pesquisa de doutorado. O Campus Google é uma iniciativa da Google presente em sete países do mundo (Brasil, Alemanha, Inglaterra, Espanha, Coréia, Israel e Polônia). Além de se tratar de um espaço que conta com uma área aberta e gratuita para o coworking, o Campus oferece um Programa de Residência com duração de seis meses para startups e empreendedores inovadores. Nesse programa, "as startups selecionadas têm 6 meses de espaço de trabalho permanente, acesso prioritário à rede de experts do Google, oportunidades para participar de programas de imersão globais, além de eventos e conteúdos exclusivos. Tudo isso sem custo para os residentes selecionados - [sendo pedido] apenas que eles se envolvam e compartilhem seus conhecimentos com a comunidade e o ecossistema de startups, contribuindo para fortalecer a cultura empreendedora do país" (CAMPUS SÃO PAULO, 2018). Disponível em: https://www.campus.co/sao-paulo/pt/about/\#residencia . Acesso em: 13/08/2020.
} 
No neoliberalismo, racional agora se torna seguir o desejo, o sonho, o talento, uma vez que tais elementos tão subjetivos ao trabalhador se encontram equiparados aos desejos, sonhos e talentos demandados pelo capital. O bom desempenho do trabalhador, dessa forma, se daria a medida em que ele se mantem em fluxo, adquirindo e oxigenando seus capitais humanos, uma vez que essa condição é fundamental para alcançar uma maior produtividade, e portanto, uma maior satisfação, uma realização nos termos do capitalismo contemporâneo. Tendo como fundamento essa racionalidade, a realidade do trabalhador se baseia naquilo que para ele seria a satisfação do seu desejo, ou seja, no seu próprio desempenho e produtividade dentro do trabalho, pois essa satisfação só se concretiza quando é possível se garantir um elo entre a dimensão subjetiva do prazer ao plano objetivo da empregabilidade. No entanto, não poderíamos falar, portanto, que tal processo seria meramente o da "desumanização como prazer" - como diria Marcuse (1985), uma vez que a vida do trabalhador, sua subjetividade, o que dele é de mais humano, está alinhado a uma perspectiva de racionalidade que opera o princípio de realidade como princípio de satisfação dos prazeres. $\mathrm{O}$ trabalhador é humano à medida que se realiza no próprio trabalho, uma vez que seu amor, ou seja, seu desejo, sua subjetividade, advém dele, pois é a partir desse princípio de racionalidade que se baseia agora sua humanidade.

\section{Quanto vale o amor no mercado?}

A teoria do capital humano é um dos alicerces que fundamenta toda a análise econômica neoliberal a respeito da relação do trabalhador e trabalho. Nesse sentido, é ela que vai sustentar toda abordagem a respeito do empreendedorismo de si (FOUCAULT, 2008). Trazer o debate do empreendedorismo de si para pensarmos a construção da ideia de amor ao trabalho facilita entender os processos econômicos e políticos sob o qual ele se insere. 
Em o Nascimento da Biopolítica (2008), Foucault trata do fundamento do pensamento neoliberal partindo de suas duas fontes: $1^{\circ}$ ) um pensamento neoliberal de origem alemã, que tinha como base o ordoliberalismo, ou seja, a perspectiva de refundar a sociedade e o Estado alemão pós-guerra tendo como terreno os princípios do mercado; e $2^{\circ}$ ) um pensamento neoliberal americano, que tinha em sua origem uma perspectiva individualista que, pelo próprio fundamento dos Estados Unidos como sociedade, encontrava um eco significativo tanto nas projeções de interesses da direita, quanto da esquerda.

Foucault (2008) observa que, teoricamente, essas linhas que dão origem ao pensamento neoliberal surgem em meados da década de 30, mas é só a partir da década de 60 que a teoria do capital humano passa a ser incorporada estrategicamente pelo que viria ser colocado em prática pelos governos neoliberais nos anos seguintes. O neoliberalismo americano se legitima ao se contrapor às políticas keynesianas, aos pactos sociais de desenvolvimento do pós-guerra e à expansão da influência da administração federal por meio dos programas econômicos e sociais. Um país que foi fundamentalmente construído tendo como princípio político o liberalismo, interpretava todas essas práticas de implementação de políticas sociais como condutas nãoliberais. Assim, a legitimidade das diretrizes neoliberais se fortalece a medida que esses programas eram encarados tanto como uma ameaça socializante por parte da direita, quanto uma ameaça imperialista e militar da expansão administrativa do governo, por parte da esquerda. É, portanto, especificamente a vertente americana do pensamento neoliberal, que tinha como base a perspectiva individualista já enraizada em seu fundamento como sociedade, que desenvolve seu foco a partir da importância dos elementos qualitativos do trabalhador na produção de capital (SCHULTZ, 1960; BECKER, 1962).

O capital humano, nesse caso, é pensado como todo o potencial humano do trabalhador que até então havia ficado inexplorado, mas que, com a transformação da racionalidade econômica a partir do neoliberalismo, passa a ser considerado como elementos ativos na produção de valor econômico. $\mathrm{O}$ trabalho, sob essa perspectiva, passa a ser pensado por meio das competências 
do trabalhador. Desloca-se, portanto, o foco das análises que tinha como objeto prioritários os mecanismos materiais como geradores de capitais e incorporase outros elementos, no caso, ligados ao comportamento e às competências do trabalhador. Por isso, quando tratamos da teoria do capital humano, devemos levar em conta que o seu desenvolvimento revela sobretudo um momento de transformação da perspectiva da análise econômica clássica para uma análise desenvolvida em consonância à racionalidade neoliberal, que se lançava em disputa, inclusive no campo teórico das interpretações econômicas. A teoria do capital humano sugere uma reinterpretação dos elementos que até então eram entendidos como externo das relações de produção do capital. Ela passa a dar base para que projeções econômicas considerassem os atributos qualitativos do trabalhador como capitais capazes de gerar produtividade dentro do mercado (FOUCAULT, 2008). Assim, a incorporação da importância acerca do capital humano na geração de renda corresponde ao início de uma fase neoliberal não só das reorganizações práticas das formas de produção, mas das próprias agendas de gestão do mercado que estavam sendo formuladas por teóricos econômicos desde a primeira metade do século XX. Todo esse aporte teórico construído ao longo desses anos, é colocado em prática por lideranças políticas como Margareth Thatcher (Reino Unido) e Ronald Reagan (EUA), ao final da década de 70, demarcando uma contraposição em relação tanto às políticas de bem-estar social quanto às insuficiências do liberalismo clássico. Tais medidas, para teóricos fundamentais do pensamento neoliberal como Hayek, seriam responsáveis por levar o liberalismo a uma nova dimensão utópica, inserindo valores quentes, humanos, à dimensão fria dos cálculos econômicos, sendo assim, capaz de atravessar desde as grandes empresas, até a subjetividade dos trabalhadores ${ }^{6}$.

O problema [neoliberal] da reintrodução do trabalho no campo da análise econômica não consiste em se perguntar a quanto se compra o trabalho, ou o

\footnotetext{
${ }^{6}$ A teoria do capital humano se liga à concepção do neoliberalismo americano, cujo principal interesse, sobretudo teórico, era trazer a dimensão do trabalho e do trabalhador para o campo ativo da análise do mercado (FOUCAULT, 2008).
} 
que é que ele produz tecnicamente, ou qual valor o trabalho acrescenta. $\mathrm{O}$ problema fundamental, essencial, em todo caso primeiro, que se colocará a partir do momento em que se pretenderá fazer a análise do trabalho em termos econômicos será saber como quem trabalha utiliza os recursos de que dispõe. Ou seja, será necessário, para introduzir o trabalho no campo da análise econômica, situar-se do ponto de vista de quem trabalha, será preciso estudar o trabalho como conduta econômica pratica, aplicada, racionalizada, calculada por quem trabalha. O que é trabalhar, para quem trabalha, e a que sistema de opção, a que sistema de racionalidade essa atividade de trabalho obedece? E, com isso, se poderá ver, a partir dessa grade que projeta sobre a atividade de trabalho um princípio de racionalidade estratégica, em que e como as diferenças qualitativas de trabalho podem ter um efeito de tipo econômico. Situar-se, portanto, do ponto de vista do trabalhador e fazer, pela primeira vez, que o trabalhador seja na análise econômica não um objeto, o objeto de uma oferta e de uma procura na forma de força de trabalho, mas um sujeito econômico ativo. (FOUCAULT, p. 307-308)

No entanto, ao visualizarmos a importância do capital humano nas relações de trabalho flexíveis, temos que problematizar o contexto de formação desses sujeitos. A partir dessa problematização, podemos reconhecer o processo pelo qual se deu a construção das subjetividades e, consequentemente, dos interesses, desejos e valores que compõem as interações. O capital humano não é algo simplesmente inato, apesar dos talentos e aptidões serem também considerados capitais humanos. Ele está diretamente relacionado com as capacidades que os indivíduos adquirem por meio de suas experiências. Por sua vez, tais capacidades estão diretamente ligadas as oportunidades que esses indivíduos são expostos ao longo das suas trajetórias de vida.

Formar capital humano, formar portanto essas espécies de competênciamáquina que vão produzir renda, ou melhor, que vão ser remuneradas por renda, quer dizer o quê? Quer dizer, é claro, fazer o que se chama de investimentos educacionais. [...] Mas os neoliberais observam que, na verdade, o que se deve chamar de investimento educacional, em todo caso os 
elementos que entram na constituição de um capital humano, são muito mais amplos, muito mais numerosos do que o simples aprendizado profissional. [...] Ou seja, o simples tempo de criação, o simples tempo de afeto consagrado pelos pais a seus filhos, deve poder ser analisado em termos de investimento capaz de constituir um capital humano. Tempo passado, cuidados proporcionados, o nível de cultura dos pais também - porque se sabe muito bem, justamente, que, para um mesmo tempo passado, pais cultos vão formar um capital humano, para uma criança, muito mais elevado do que se não tiverem o mesmo nível de cultura -, o conjunto dos estímulos culturais recebidos por uma criança: tudo isso vai constituir elementos capazes de formar um capital humano. (FOUCAULT, 2008, p. 315-316)

A necessidade dessa nova perspectiva se daria na medida em que o capital passava a visualizar a rentabilidade ou a relação econômica presente em conteúdos e comportamentos que até então eram colocados como externos à grade econômica e sua análise. É importante salientar, também que esse momento de expansão e fortalecimento das ideias neoliberais, ou seja, a década de 70, corresponde a um período de intensa crise do capital, onde ele buscava por alternativas de reconfiguração não só das suas formas de produção, mas da sua legitimidade em meio as sociedades ocidentais (BOLTANSKI \& CHIAPELLO, 2009; LAVAL \& DARDOT, 2016).

Ao considerar o trabalhador como um sujeito econômico ativo, teóricos neoliberais passam a pensar o salário como uma renda cujo capital seria mobilizado por uma série de fatores psicológicos, físicos, comportamentais e intelectuais. Dessa maneira, o trabalho comportaria um capital, uma competência. O capital humano seria, portanto, tudo aquilo que comporia a realidade do trabalhador e que seria capaz de influir sobre sua aptidão em realizar determinada tarefa. Assim, como pontua López-Ruiz (2007),

O capital humano [...] é um conjunto de capacidades, destrezas e talentos que, em função do avanço do capitalismo, deve se tornar valor de troca. [...] "o humano", um conjunto de habilidades, destrezas e aptidões próprias dos homens, adquire valor de mercado e se apresenta como forma capital - 
entendido como uma soma de valores de troca que serve de base real a uma empresa capitalista. Assim, a partir de um determinado momento que chamamos de invenção do capital humano, o capital, conceito necessariamente abstrato, passa a se apresentar coberto com roupas humanas; vestindo características e atributos até então apenas vistos no homem. O capital, desta vez, concretiza-se não em dinheiro ou mercadorias, mas em atributos humanos; o capital é investido de formas humanas. (LÓPEZ-RUIZ, 2007, 183-184)

Dessa forma, as relações sociais do trabalhador, sua educação, ou seja, elementos até então externos à grade econômica passam a ser constituintes dos comportamentos mais ou menos rentáveis, uma vez que, sob essa análise, quanto maior a quantidade de capital humano agregado ao trabalhador, maiores são as oportunidades desse trabalho em revertê-lo em uma melhor renda (FOUCAULT, 2008).

Se olharmos para o papel que o capital humano desempenha dentro do processo de reestruturação produtiva, podemos ver que ele é um dos elementos que se insere na própria concepção do homem a respeito de si próprio e da sua produtividade. Nesse ponto, vemos que sociedade pósfordista rompeu com os paradigmas de produção, mas também com paradigmas sobre como o mercado deveria se relacionar com os indivíduos em sociedade. A economia planificada das sociedades industriais, até então adequada para as massas, deveria agora atender às multidões, as quais ela própria, pela expansão do consumo, havia dado as condições de proliferar. Nessa mesma esteira, os avanços das tecnologias e a ampliação das formas de distribuição dos produtos e das informações promoveu um outro tipo de relação entre os indivíduos e suas identidades. A flexibilidade e a diversidade se organizam agora sobretudo na dimensão das subjetividades e na representação desses sujeitos sobre si próprios e à realidade que os cerca. A multidão assume diversas pautas, interesses e desejos e não se trata de atendê-los, mas de permitir e estimular sua produção. A humanidade e sua potência desejante, torna-se o próprio capital. 
[...] De um lado, as relações de exploração capitalista estão se ampliando em toda parte, não limitadas à fábrica mas tendendo a ocupar todo o terreno social. De outro, as relações sociais cobrem completamente as relações de produção, tornando impossível qualquer externalidade entre a produção social e a produção econômica. A dialética entre as forças produtivas e o sistema de dominação já não tem um lugar determinado. As próprias qualidades do poder do trabalho (diferença, medida e determinação) já não podem ser captadas, e, da mesma forma, a exploração não pode mais ser localizada e quantificada. De fato, não são as atividades produtivas específicas que tendem a ser objeto de exploração e dominação, mas a capacidade universal de produzir, isto é, a atividade social abstrata e seu poder inclusivo. Esse trabalho abstrato é uma atividade sem lugar certo, e ainda assim é muito poderoso. É o conjunto cooperativo entre cérebros e mãos, mentes e corpos; é simultaneamente o não fazer parte e a difusão social criativa do trabalho ativo; é o desejo e esforço da miríade de operários móveis e flexíveis; e ao mesmo tempo é energia intelectual e linguística e construção comunicativa de uma multidão de operários intelectuais e afetivos. (HARDT \& NEGRI, 2001, p. 228-229)

Nesse sentido, dentro dos arranjos produtivos das novas formas de trabalho, a diversidade é usada como um ponto positivo. Motiva-se constantemente os talentos e atributos humanos dos trabalhadores. Não mais se trata de ser um profissional conhecedor da técnica e das plataformas de trabalho. Deve-se agora ser um trabalhador apto a se relacionar com outros trabalhadores e, sobretudo, com a empresa. Por isso, observamos que o desempenho do trabalhador nos novos modelos de trabalho flexíveis estaria, portanto, intimamente ligado à sua capacidade de mobilidade na rede e consecutivamente, da implementação de seu capital humano a partir dela. Dito de outra maneira, o trabalhador se vê agora como o único responsável pelo seu sucesso e produtividade.

A figura do empreendedor é por si só uma peça chave no capitalismo contemporâneo que se baseia na filosofia neoliberal. Ele, como próprio capital humano, mobiliza a partir de seu perfil inúmeros capitais sociais úteis para a reprodução do capitalismo atual. Ele "percebe a mudança e lida com 
oportunidade", se mantendo flexível em meio as instabilidades, podendo lucrar com elas (PAULINO \& ROSSI, 2003, p. 207). O empreendedor concentra em si a intensa busca pela valorização e ampliação de seus capitais. Tal personalidade é incansavelmente exaltada pelos novos modelos de trabalho flexível, como por exemplo as startups, modelos de trabalho que colocam em jogo a subjetividade dos indivíduos em relação a sua produtividade (ZANON, 2019). Da mesma forma, muito dessa personalidade não se dá a partir do trabalho, mas constrói-se antes dele, baseada em valores e premissas veiculadas por um novo espírito capitalista que atravessa as sociedades pós-fordistas (BOLTANSKI \& CHIAPELLO, 2009).

Nessa esteira, Foucault (2008) pontua algo elementar, e que nos ajuda a dar fundamento em nossas observações sobre a transformação da relação entre trabalho e trabalhador e, consequentemente, sobre sua própria alienação.

A aptidão a trabalhar, a competência, o poder fazer alguma coisa, tudo isso não pode ser separado de quem é competente e pode fazer essa coisa. Em outras palavras, a competência do trabalhador é uma máquina, sim, mas uma máquina que não se pode separar do próprio trabalhador, o que não quer dizer exatamente, como a crítica econômica, ou sociológica, ou psicológica dizia tradicionalmente, que o capitalismo transforma o trabalhador em máquina e, por conseguinte, o aliena. Deve-se considerar que a competência que forma um todo com o trabalhador e, de certo modo, o lado pelo qual o trabalhador é uma máquina, mas uma máquina entendida no sentido positivo, pois é uma máquina que vai produzir fluxos de renda. (FOUCAULT, 2008, 309)

Assim, tendo a própria grade de análise e de considerações modificado, seria preciso também uma teoria que desse conta dos elementos fugidios do ponto de vista da análise tradicional. Apesar de Foucault ter notado toda essa transformação e refletido exaustivamente sobre ela, foram Deleuze e Guattari que desenvolveram suas reflexões no sentido de elaborar noções a respeito de uma economia desejante, que articula os sentimentos, a subjetividade e a própria vida do trabalhador em função da reprodução do capital. Ambos foram 
protagonistas de um pensamento social que comungaria junto à psicanálise, uma vez que para eles "o desejo é da ordem da produção; toda produção é ao mesmo tempo desejante e social” (DELEUZE \& GUATTARI, 2011, p. 390). Os dois autores foram também responsáveis por observarem que, apesar das críticas dos teóricos neoliberais a respeito da consideração intensiva de Marx sobre o trabalho abstrato, é a partir dessa abstração que se encontra a chave para as revoluções capitalistas, ou seja, para a perpetuação do estímulo produtivo.

Marx resume tudo isto ao dizer que a essência subjetiva abstrata só é descoberta pelo capitalismo para ser novamente encadeada, alienada, é verdade que não mais como objetividade no elemento exterior e independente, mas no próprio elemento subjetivo da propriedade privada: "Outrora, o homem era exterior a si próprio e encontrava-se num estado de alienação real; agora, esse estado mudou em ato de alienação, de espoliação”. Com efeito, é a forma da propriedade privada que condiciona a conjunção dos fluxos descodificados, isto é, sua axiomatização num sistema onde o fluxo dos meios de produção, como propriedade dos capitalistas, é reportado ao fluxo do trabalho dito livre, como "propriedade" dos trabalhadores (de modo que as restrições estatais sobre a matéria ou o conteúdo da propriedade privada não afetam de modo algum essa forma). [...] Em outros termos, o capitalismo implica certamente a derrocada das grandes representações objetivas determinadas, é claro que em proveito da produção como essência interior universal, mas nem por isso ele sai do mundo da representação, operando tão somente uma vasta conversão desse mundo ao dar-lhe a forma nova de uma representação subjetiva infinita. (DELEUZE \& GUATTARI, 2011, p. 300)

Nesse processo de incorporação dos desejos capitais, uma racionalidade capitalística é absorvida pelos trabalhadores como a realização de uma fantasia futurista do fim do trabalho. No entanto, escapa às suas percepções que o trabalhador como elemento dessa relação, ainda é o elo de exploração. A flexibilidade, portanto, é muito mais uma característica inerente de uma fase do capitalismo que, devido a um momento de crise fordista, precisou recorrer à dinâmicas produtivas pautadas na diversidade e rapidez. No 
entanto, ela se tornou nesse processo em um próprio capital humano, a ser adquirido e desenvolvido por parte dos trabalhadores, fazendo agora parte de sua identidade não só dentro do trabalho, mas também em suas relações externas de sociabilidade, já que a flexibilidade proporciona a mobilidade necessária para a acumulação de capital humano em um contexto tão instável como o de agora. O trabalhador flexível é agora não só aquele que disponibiliza seus horários e competências às ordens das incertezas do mercado, mas aquele que, a partir dessas demandas e acorda seus desejos em função de uma maior produtividade capital.

\section{"Faça porque você ama"}

O espírito empreendedor, que faz equivaler o indivíduo a uma própria empresa, a empresa de si mesmo, destinada a rentabilizar seus capitais humanos, é um dos principais elementos constituintes da nova racionalidade neoliberal que diz respeito a gestão econômica, mas também a social e política (FOUCAULT, 2008; LAVAL \& DARDOT, 2016). Partindo da ideia de que a renda atribuída ao trabalhador extrapola a dimensão quantitativa e temporal - ou seja, o simples dispêndio de horas em relação a uma determinada atividade -, constrói-se um perfil de trabalhador que seria equivalente ao empresário de si mesmo. Modifica-se, assim, a performance do homo oeconomicus, que na realidade do liberalismo clássico era compreendido apenas como o parceiro da troca. Agora, esse homo oeconomicus mobiliza dimensões que estão além das materialidades da troca. Sua renda está vinculada aquilo que é externo as realizações quantitativas, sendo assim atribuída ao seu próprio capital humano. Ele é o seu próprio capital, seu produtor e sua fonte de renda (FOUCAULT, 2008, 311).

Uma figura que ilustra bem essa nova racionalidade é a de Steve Jobs ${ }^{7}$, um dos mais conhecidos disseminadores da máxima “do what you love”. Assim

\footnotetext{
${ }^{7}$ Steve Jobs foi co-fundador da Apple Computers, juntamente com Steve Wozniak. Sob a liderança de Jobs, a empresa foi pioneira em uma série de tecnologias revolucionárias, incluindo o iPhone e o iPad. Biografia disponível em: http://www.biography.com/people/steve-jobs-9354805 . Acesso em: 16 dez. 2014
} 
como toda sua história na fundação de uma das maiores empresas de tecnologia informacional na atualidade, Jobs é considerado um modelo bem sucedido a ser seguido e, baseando-se no seu amor e em sua resiliência em meio a condução de sua história profissional, inúmeros jovens trabalhadores passaram a espelhar-se nele quando se tratava se suas carreiras profissionais. O amor aliado ao trabalho era o que dava tom a suas falas e conferências públicas. O mais conhecido desses discursos foi realizado durante uma cerimônia de formatura da Universidade de Stanford, em 2005, nos Estados Unidos ${ }^{8}$. Em um dos trechos, ele salienta:

Seu trabalho vai preencher uma parte grande da sua vida, e a única maneira de ficar realmente satisfeito é fazer o que você acredita ser um ótimo trabalho. E a única maneira de fazer um excelente trabalho é amar o que você faz. Se você ainda não encontrou o que é, continue procurando. Não sossegue. Assim como todos os assuntos do coração, você saberá quando encontrar. E, como em qualquer grande relacionamento, só fica melhor e melhor à medida que os anos passam. Então continue procurando até você achar. Não sossegue. (JOBS, 2005)

Nesse novo panorama, a produtividade do trabalhador dependeria, portanto, não apenas da quantidade de tempo que ele reverte em horas de trabalho, mas dos elementos inatos e adquiridos que ele disponibiliza para essa atividade. Consequentemente, o trabalhador se insere intimamente na esfera do consumo, uma vez que é a partir do consumo que ele aumentará seu capital humano a fim de usá-lo de forma satisfatória como fonte de renda. A questão é que, pensar a renda sob a perspectiva do capital humano e as relações e instituições sociais como ferramentas capazes de criar uma maior satisfação dos indivíduos frente a sua realização no trabalho, conduz a um tipo de racionalidade governamental que, para os neoliberais, possibilitaria o relacionamento positivo entre mercado e sociedade (FOUCAULT, 2008).

\footnotetext{
8 Discurso disponível em: https:/www.youtube.com/watch?v=s9E6XfJPAMM. Acesso em: 16 ago. 2020 .
} 
Essa decomposição do trabalho em capital e renda induz, evidentemente, certo número de consequências importantes. Em primeiro lugar, sendo o capital assim definido como o que torna possível uma renda futura, renda essa que é o salário, vocês veem que se trata de um capital que é praticamente indissociável de quem o detém. E, nessa medida, não é um capital como os outros. [...] Não é uma concepção da força de trabalho, é uma concepção do capital-competência, que recebe, em função de variáveis diversas, certa renda que é um salário, de sorte que é o próprio trabalhador que aparece como empresa de si mesmo. [...] Uma economia feita de unidades-empresas, uma sociedade feita de unidades-empresas: é isso que é, ao mesmo tempo, princípio de decifração ligado ao liberalismo e sua programação para a racionalização tanto de uma sociedade como de uma economia. (FOUCAULT, 2008, p. 310311)

O que acontece nesse momento são transformações na organização do capitalismo, que, consequentemente passam a afetar a subjetividade e a identidade dos trabalhadores. A maneira como eles vêm a si próprios em relação aos seus trabalhos se modifica, assim como os anseios que eles passam a envolver no que diz respeito a sua vida profissional. Um dos exemplos clássicos dessas transformações é a ideia de que o trabalhador nessa nova fase deve "vestir a camisa da empresa", o que significa identificar-se com ela, e fazer com que de certa forma, toda dimensão que até então estava externa à sua atividade laboral, seja agora envolvida em função do seu trabalho. "Vestir a camisa da empresa" sugere que o trabalhador a tenha como uma segunda pele; que esteja sempre disponível às suas demandas e que os princípios da empresa sejam agora seus próprios princípios. Como Lima (2010) observa:

O discurso empresarial enfatiza, ainda, um perfil de trabalhador marcado pela flexibilidade frente às mudanças, investindo em sua formação permanente e aberto a novos desafios, um empreendedor de si mesmo que garantiria, dessa forma, sua empregabilidade e permanência num mercado em contínua transformação. (LIMA, 2010, p. 160) 
Fromm (2000) desenvolve, já em 1956, uma análise nesse sentido sobre as condutas e condições do homem moderno.

O capitalismo moderno necessita de homens que cooperem sem atrito e em amplo número; que queiram consumir cada vez mais; e cujos gostos sejam padronizados e possam ser facilmente influenciados e previstos. Necessita de homens que se sintam livres e independentes, não submissos a qualquer autoridade, ou princípio, ou consciência - e, contudo, desejosos de ser mandados, de fazer o que se espera deles, de adequar-se em fricção à máquina social; que possam ser guiados sem força, dirigidos sem líderes, impulsionados sem alvos - exceto o de produzir bem, estar em movimento, funcionar, ir adiante (FROMM, 2000, p. 66)

O que vemos agora é, portanto, um vínculo afetivo, emocional, entre a subjetividade do trabalhador e o local em que trabalha. No entanto, toda essa mobilização do trabalhador em função do seu trabalho aparece a ele não como uma anulação do primeiro em relação ao segundo, mas como um avanço no que diz respeito a sua autonomia. "Vestir a camisa da empresa" é apresentado ao trabalhador como uma forma de ganhar legitimidade, e consequentemente, posição ativa em suas ações dentro do trabalho, fundamentando-se assim, como uma parceria entre trabalhador e empresa.

Podemos dizer que, quando Weber (2004) se dispõe a pensar sobre o espírito do capitalismo - e como ele se vale dos atributos das ações racionais dos indivíduos em sociedade, ele já considera de maneira explícita as formas pelas quais o trabalho é incorporado à subjetividade do trabalhador. Dar foco a essa relação dialógica, portanto, não é algo novo dentro das análises sociais sobre capital e trabalho. O que se implementa nessa nova etapa são as formas pelas quais o caráter empreendedor do trabalhador é invocado, ou seja, como esse novo perfil de trabalhador é capacitado a mobilizar desejos, valores e motivações que em grande medida são usufruídos pela própria dinâmica do capital. O que vemos é uma série de valores, subjetivos e simbólicos, que passam a ser organizados como capitais por parte dos trabalhadores. Ser um trabalhador flexível, aberto a novos contatos, amigável, criativo não se trata 
mais de meras qualidades que o distingue em personalidade, mas trata-se agora de atributos que se relacionam diretamente com sua empregabilidade. Dessa maneira, empreender sobre si próprio significa cada vez consumir os padrões, sobretudo subjetivos, demandados pelo mercado. No entanto, esse consumo não vai ser entendido como um dispêndio, pelo contrário: será a maneira pela qual esse trabalhador promoverá sua satisfação, sua realização, ou, como diria Marcuse (1975) sua humanidade a partir do trabalho, a qual corresponde agora, consecutivamente, a uma maior produtividade no mercado.

\section{Considerações finais}

Em meio a perspectiva do empreendedorismo de si, podemos ver como a dimensão dos desejos e das emoções, articulados ao afeto pelo trabalho nas subjetividades de trabalhadores, passa a ser incorporado pelas demandas do próprio capitalismo. Uma vez que agora a realidade baseada na racionalidade política neoliberal considera que: 1) todos podem alcançar seus objetivos, dado às inúmeras tecnologias e oportunidades da vida moderna; 2) a desigualdade material não é mais entendida como fruto de uma exploração desigual, mas como resultado de um desempenho individual insatisfatório e que; 3) a identidade, por mais diversos que sejam seus componentes, está sempre passível de encontrar seu eco no mercado. Assim, a dimensão subjetiva é acessada a fim de repassar a responsabilidade do fracasso ao próprio indivíduo. O resultado dessa equação é que retira-se o foco das explorações elementares e externas à vontade do trabalhador, contribuindo para o domínio e a reprodução de um sistema em que as oposições são apagadas de maneira dissimulada. Dessa forma, em um momento onde as fragmentações e fragilidades permeiam as relações em sociedade e, consequentemente, a flexibilidade - ou resiliência, como convenciona-se clamar ultimamente passa a ser intensamente demandada como atributo não só do ambiente de trabalho, mas da própria vida cotidiana, o amor passa também a ser um valor mobilizado a fim de criar não só uma integração, mas também a devida 
legitimidade para condutas de esperança e conformismo em condições tão instáveis.

O indivíduo, visto em sua forma passiva e antes envolto às estratégias de disciplinarização do corpo a favor do trabalho, é chamado nesse novo momento a estar ativo, sensível e ciente em relação às suas atividades laborais, e tal condição passa a ser estimulada tanto do ponto de vista ideológico quanto da própria experiência produtiva. Dessa forma, nesse movimento de reestruturação, as dinâmicas de uma nova forma de acumulação capitalista ganharam força e legitimidade entre os trabalhadores ao aliar em seus discursos organizacionais demandas advindas principalmente de reivindicações críticas em relação ao sistema capital. Isso deixa mais evidente como a partir de então se dá a incorporação de valores que eram relacionados a uma crítica ao capital - como cooperação, participação e afetos - nesse projeto, promovendo uma mentalidade capaz de disfarçar as nuances de exploração presente nas relações entre trabalhador e capital, ou, como apontam Boltanski \& Chiapello (2009), um novo espírito do capitalismo. A contribuição desses autores - assim como todos os outros que trouxemos como referência nessa breve discussão - nos ajuda a refletir e desmistificar fatos sobre como a agenda pós-fordista - que se fundamenta nos princípios neoliberais das relações entre mercado e sociedade -, passa a cooptar as reivindicações das multidões, principalmente a dos trabalhadores, e as transforma em fermento para construir novos arranjos para estratégias já conhecidas.

Assim, é o trabalhador que deve se manter constantemente disposto a se renovar e isso passa a ser classificado como liberdade diante das práticas rígidas das fábricas e escritórios introduzidas até então pela rigidez fordista. O desejo e o afeto pelo trabalho são mobilizados a tal ponto que torna-se impossível não amar o trabalho, e amando-o, não reconhecer suas facetas onerosas. Conflitos elementares passam a ser atenuados e justificados, uma vez que tais problemáticas passam a ser interpretadas como consequências normais dentro do processo de estar empreendendo sobre si mesmo. 
Nosso objetivo aqui foi, em linhas gerais, realizar sobretudo uma reflexão teórica sobre os fundamentos do neoliberalismo, demonstrando para isso como o amor o trabalho é agora parte das caraterísticas fundamentais do próprio trabalhador como empreendedor de si e, sendo assim, mais um dentre os capitais humanos a serem mobilizados. O que se vê, portanto, na realização da história é a construção de um novo perfil junto a toda reivindicação por autonomia e melhores condições de trabalho, originalmente formuladas e demandadas de maneira crítica pelos trabalhadores. Buscamos demonstrar como agora essas reivindicações são incorporadas estrategicamente pelo próprio capital em sua fase pós-fordista. O trabalhador ideal é flexível e motivado a ampliar seus capitais humanos como forma de garantir melhores posições e liberdade dentro do trabalho. Não se trata necessariamente de uma alienação tradicional. Algo de mais perverso se constitui. A própria representação e consciência sobre si e sobre seu contexto é reconfigurado de maneira a ser promovida e exaltada pelos próprios trabalhadores. Suas subjetividades são organizadas sob o objetivo de dar coerência - mas também um significado positivo - às fragmentações e instabilidades que passam a ser submetidos a partir de então. A exploração não é mais evidente, pois as repostas às demandas por autonomia e liberdade aparecem dentro das oportunidades que o discurso empreendedor disponibiliza como algo fácil de ser acessado por aquele trabalhador que realmente ama o que faz.

\section{Referências}

ALBORNOZ, S. Atração passional, trabalho e educação em O novo mundo industrial e societário (1829), de Charles Fourier. Cadernos de Psicologia Social do Trabalho, São Paulo, v. 10, n. 1, p. 1-19, 2007. Disponível em: <http://www.revistas.usp.br/cpst/article/view/25806>. Acesso em: 09 ago. 2020.

BARROS, J. A. Os falanstérios e a crítica da sociedade industrial: revisitando Charles Fourier. Mediações, Londrina, v. 16, n. 1, p. 239-255, mai. 2011. Disponível 
< $\underline{\text { http://www.uel.br/revistas/uel/index.php/mediacoes/article/viewFile/7752/8 }}$ 503>. Acesso em: 29 ago. 2020.

BOLTANSKI, L.; CHIAPELLO, È. O novo espírito do capitalismo. Tradução Ivone C. Benedetti, revisão técnica Brasílio Sallum Jr. 1. ed. São Paulo: Martins Fontes, 2009.

DELEUZE, G.; GUATTARI, F. O Anti-édipo. Tradução Luiz B. L. Orlandi. 2. ed. São Paulo: Editora 34, 2011. 560 p. (Coleção TRANS)

FOUCAULT, M. Nascimento da Biopolítica: curso dado no Collège de France (1978-1979). Tradução Eduardo Brandão, revisão técnica Cláudia Berliner. 3. ed. São Paulo: Martins Fontes, 2008. 475 p. (Coleção tópicos)

FOURIER, C. Le nouveau monde industriel et sociétaire. Édition de 1845. Paris: Éditions Flammarion: 1973. 568 p. (Collection Nouvelle bibliothèque romantique).

FROMM, E. A arte de amar. Tradução Eduardo Brandão. 1. ed. São Paulo: Martins Fontes, 2000.

HARDT, M.; Negri, A. Império. Tradução Berilo Vargas. 2. ed. São Paulo, Rio de Janeiro: Editora Record, 2001.

STEVE, J. Discurso Stanford Completo e Legendado. [S.l.; s.n], 2005. 1 vídeo (14min41s). Publicado pelo canal Marcus Pessoa. Disponível em:

https://www.youtube.com/watch?v=s9E6XfJPAMM . Acesso em: 16 ago. 2020. LAVAL, C.; DARDOT, P. A nova razão do mundo: ensaio sobre a sociedade neoliberal. Tradução Mariana Echaclar. São Paulo: Boitempo, 2016..

LIMA, J. Participação, empreendedorismo e autogestão: uma nova cultura do trabalho? Sociologias, Porto Alegre, ano 12, n. 25, p. 158-198, set./dez. 2010. LOPEZ-RUIZ, O. J. Os executivos das corporações transnacionais e o espírito do capitalismo: capital humano e empreendedorismo como valores, Rio de Janeiro, Azougue, 2007.

MARCUSE, H. Eros e a civilização: uma interpretação filosófica do pensamento de Freud. Tradução Álvaro Cabral. 6. ed. Rio de Janeiro: Zahar, 1975.

MARQUES, B. R. Fourier: por um novo mundo amoroso. Núcleo de Estudos Contemporâneos, UFF.

Disponível em: 
<http://www.historia.uff.br/nec/sites/default/files/Fourier.pdf $>$. Acesso em: 16 jul. 2020.

PAULINO, A. D.; ROSSI, S. M. M. Um estudo de caso sobre Perfil Empreendedor: características e traços de personalidade empreendedora. In: $E G E P E$ - encontro de estudos sobre empreendedorismo e gestão de pequenas empresas. Ano 3., Brasília: UEM/UEL/UnB, 2003, p. 205-220, 2003.

SAHLINS, M. Ilhas de história. 2. ed. Rio de Janeiro: Zahar, 2011. 252 p.

SCHULTZ, T. W. O capital humano: investimento em educação e pesquisa. Rio de Janeiro: Zahar, 1973.

ZANON, B. Não era amor, era cilada: startups, coworkings e a mobilização do desejo pelo mundo do trabalho. 2019. 185 f. Tese (Doutora em Sociologia) Universidade Federal de São Carlos, São Carlos, 2019.

Recebido em maio de 2020. Aprovado em julho de 2020 . 